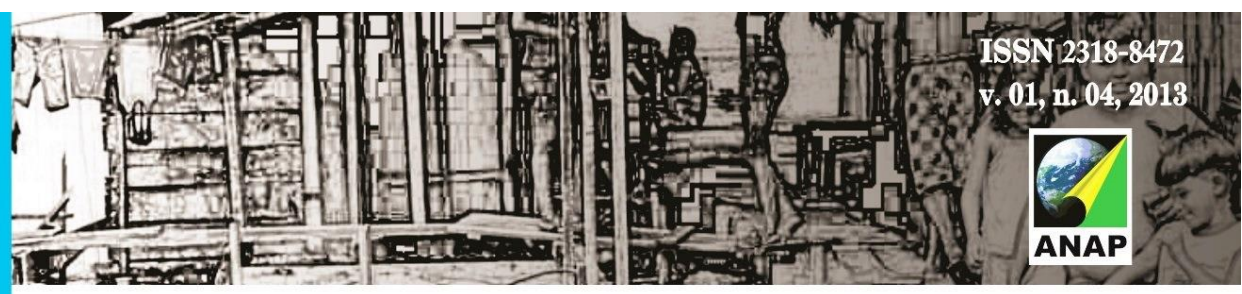

Gerenciamento de Cidades

Título do Trabalho

\title{
INFRAESTRUTURA VERDE E PAISAGEM URBANA: PROJETO PAISAGÍSTICO PARQUE NAÇÕES NORTE
}

Nome do Autor Principal

Eduardo Henrique Rodrigues

Nome do Orientador

Maria Fernanda Nóbrega dos Santos

Instituição ou Empresa

UNIVERSIDADE SAGRADO CORAÇÃO - USC - BAURU

E-mail de contato

dotinet@hotmail.com

Palavras-chave

Drenagem Urbana. Infraestrutura Verde. Sustentabilidade.

\section{INTRODUÇÃO}

Atualmente, mais da metade da população mundial vive em cidades: estima-se que cerca de 3 bilhões de pessoas vivem sob tetos em centros urbanos. Desse modo, fica evidenciado que o acelerado crescimento urbano - pelo qual tem atravessado os países, principalmente aqueles em desenvolvimento - se conduzido de maneira inadequada, gera problemas estruturais nas cidades e, por conseguinte, no ambiente em seu entorno. As 


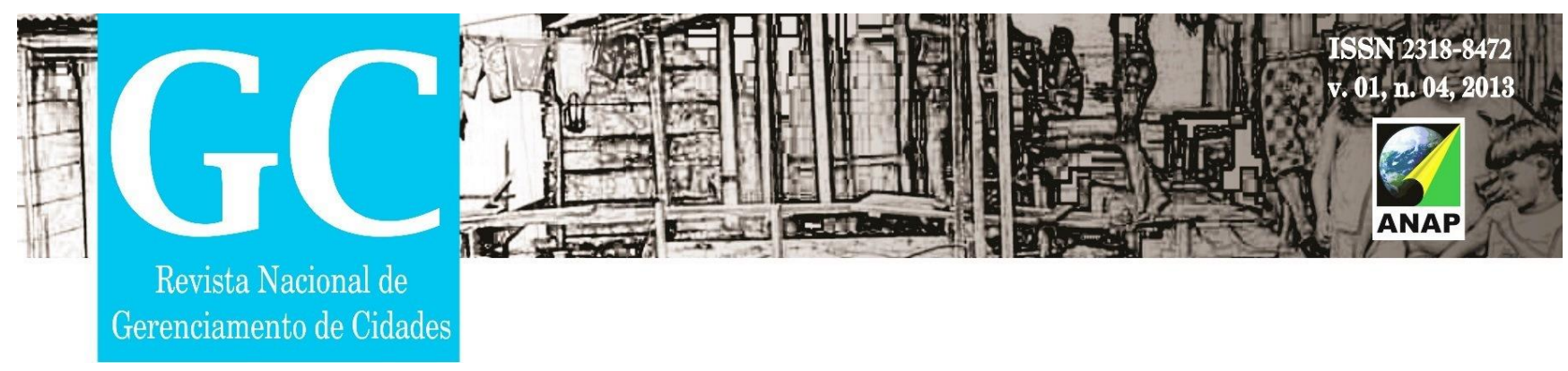

cidades podem ser vistas então, como um dos principais agentes responsáveis pelos impactos ambientais gerados no mundo. (MIANA, 2010).

Os problemas consequentes da falta de controle da drenagem das águas pluviais estão sendo um doloroso embate para grandes cidades brasileiras. Segundo Mascaró e Yoshinaga (2005, p. 21), "Um dos maiores desafios do crescimento equilibrado e duradouro das populações é provê-las de serviços urbanos em quantidade e qualidade suficientes." Desta maneira, ressalta-se a importância dos projetos de planejamento para as águas pluviais.

Em cidades como: São Paulo e Rio de Janeiro, e ainda no estado de Santa Catarina, pode-se observar que, cada vez mais, as áreas urbanas estão sendo impermeabilizadas, cabendo única e exclusivamente, a responsabilidade do destino final das águas pluviais ao sistema de drenagem existente. No município de Bauru/SP essa realidade torna-se bastante frequente.

Além disso, devido à maneira como se estabelece a forma da ocupação territorial nos tempos atuais, pode-se considerar o presente sistema de drenagem pluvial urbano como sendo insuficiente à demanda pois, além de interromper uma parte do ciclo natural das águas pluviais, reduz sensivelmente a infiltração no solo. Neste sentido, o sistema de drenagem urbana trabalha, unicamente, na captação da água precipitada nas vias urbanas e através das redes de tubulações e das galerias pluviais conduzindo ao curso d'água mais próximo, que na maioria das vezes está canalizado (sofrendo influências em seu leito) (GORSKI, 2010).

Como resposta às questões levantadas anteriormente, a Infraestrutura Verde pode ser considerada uma possibilidade na minimização dos problemas de drenagem pluvial urbana, e trabalhando junto ao sistema de drenagem existente podem proporcionar espaços verdes integrados em que se possam conceber maiores relações ecossistêmicas (HERZOG, 2010).

Desse modo, admite-se que os estudos que aplicam estes conceitos desenvolvidos com o uso do instrumento em Infraestrutura Verde podem proporcionar um melhor destino às águas pluviais, e assim reduzir os impactos no ambiente. Assim sendo, o presente 


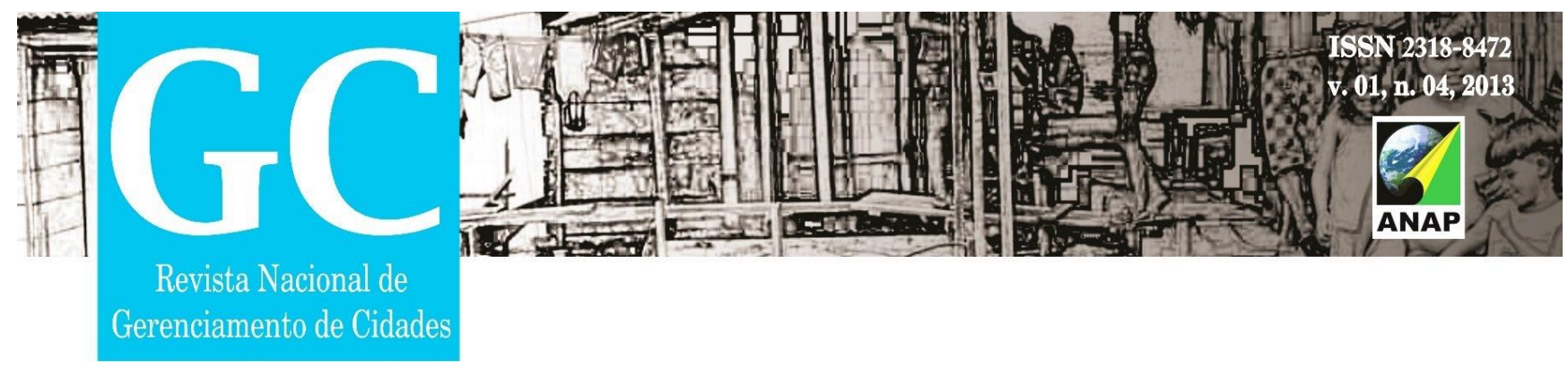

trabalho visa desenvolver um projeto paisagístico em um espaço urbano, fazendo uso das técnicas de Infraestrutura Verde, no munícipio de Bauru/SP.

\section{OBJETIVO GERAL}

Este trabalho tem como objetivo a elaboração de uma proposta projetual empregando as técnicas de Infraestrutura Verde, para a mitigação dos problemas relacionados à drenagem de águas pluviais em uma área no município de Bauru/SP.

\section{OBJETIVO ESPECÍFICO}

$\checkmark$ Efetuar uma pesquisa bibliográfica visando aprofundar os conhecimentos sobre as técnicas e diferentes tipologias projetuais de Infraestrutura Verde, verificando ainda a existência de diferentes projetos paisagísticos como base à pesquisa, que possam ser aplicadas à área de estudo.

$\checkmark$ Realizar uma caracterização da área estudada, contendo: levantamento topográfico; levantamento climático; e levantamento de drenagem urbana da área.

$\checkmark$ Contribuir para o avanço e disseminação do conhecimento a respeito da Infraestrutura Verde, colaborando na divulgação destes métodos inovadores de intervenção projetual, no que se refere à drenagem pluvial urbana.

\section{METODOLOGIA}

Para o desenvolvimento do presente trabalho de pesquisa foi realizada uma revisão bibliográfica a respeito do tema "drenagem urbana," com aprofundamento em Infraestrutura Verde, promovendo uma variada gama de conhecimentos que possam orientar e subsidiar a elaboração de propostas de intervenção urbana. 


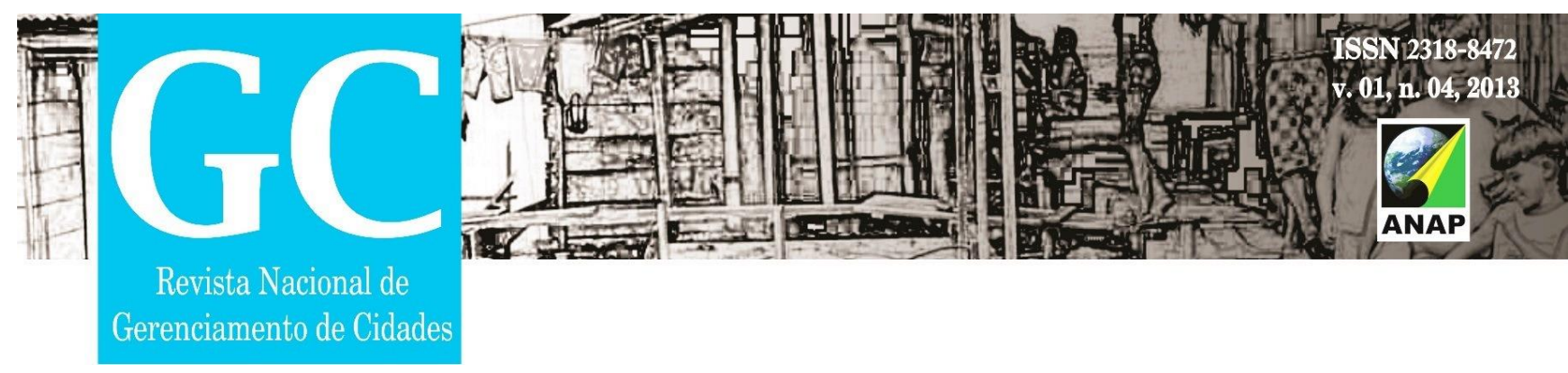

A pesquisa científica foi dividida em etapas, a fim de organizar os processos metodológicos e também delinear os parâmetros utilizados em cada etapa, conforme detalhado a seguir nos próximos itens.

\subsection{CARACTERIZAÇÃO DA ÁREA E DIAGNÓSTICO}

Para iniciar o trabalho, foi realizado um levantamento dos aspectos físicos da área de trabalho: a Avenida Nações Unidas e seu entorno. Esse levantamento se constitui: do levantamento topográfico, do levantamento climático, do levantamento de uso e ocupação do solo e do levantamento de drenagem urbana da área.

\subsection{ANÁLISE DE DADOS E DEFINIÇÃO DOS CRITÉRIOS DE INFRAESTRUTURA VERDE}

Foram analisado os dados obtidos na etapa anterior visando aprofundar o conhecimento sobre a situação presente da área objeto de estudo. A seguir, com base na análise dos dados foram definidos os critérios de Infraestrutura Verde a serem adotados no presente projeto de intervenção urbana na Avenida Nações Unidas.

\subsection{PROPOSTA DE INTERVENÇÃO URBANA NA ÁREA}

A proposta de intervenção urbana na área objeto de estudo foi desenvolvida após as análises das informações coletadas, utilizando-se os princípios de Infraestrutura Verde mais adequados às condições levantadas. Como produto desta etapa, foi desenvolvido o plano de necessidades para o Projeto do Parque Nações Norte e uma setorização projetual da sua implantação, com base nos conceitos de Infraestrutura Verde.

\section{RESULTADO}




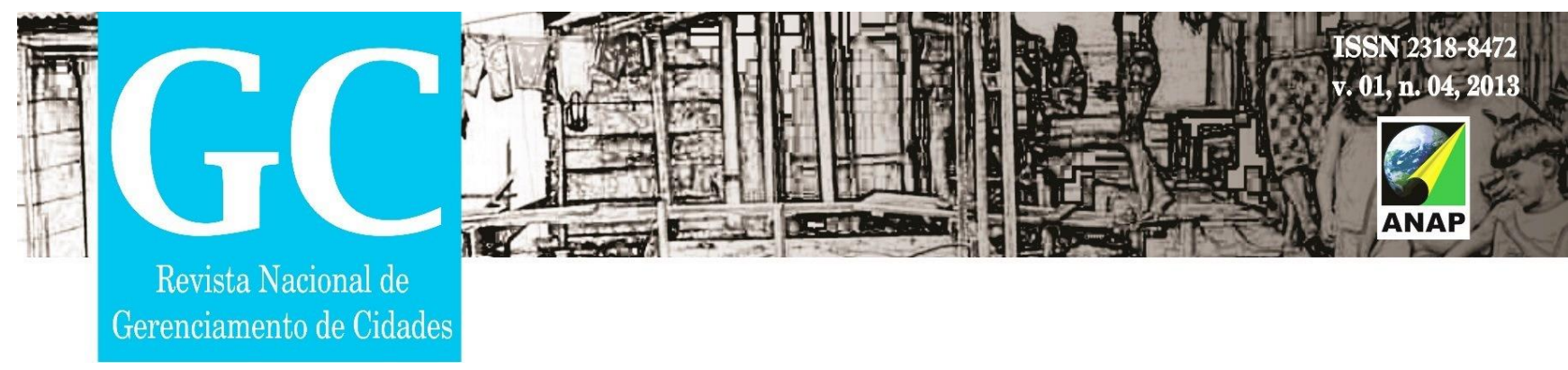

Conforme foi observado no desenvolvimento do trabalho, foi definida uma área de intervenção localizada na Avenida Nações Unidas, precisamente entre a Avenida Moussa Nakhl Tobias na intersecção com o início da Avenida Nações Norte, como é popularmente conhecida pelos habitantes da cidade de Bauru, ao lado da Empresa Maxxi Atacado. A área necessita de extremo cuidado com relação à drenagem pluvial, ao tratamento do solo para não sofrer processos erosivos, ter melhor integração com a cidade, e sobretudo, não se transformar em uma área problema no município de Bauru.

Visando uma melhor integração entre o Projeto do Parque Nações Norte que será desenvolvido e o município de Bauru, o projeto paisagístico de aproximadamente $31.435,7 \mathrm{~m}^{2}$ de área. Deste modo, para o desenvolvimento da proposta projetual do projeto paisagístico foi estabelecido o plano de necessidades:

$\checkmark$ Instalação de mobiliário urbano, como: bancos, lixeiras, e postes de iluminação;

$\checkmark$ Instalação de quadra de futebol;

$\checkmark$ Utilização de gabiões vegetados, como técnica de reforço nas partes íngremes do terreno;

$\checkmark$ Uso de pisos porosos no calçamento para os pedestres;

$\checkmark$ Uso de plantas nativas do município de Bauru e da região;

$\checkmark$ Instalação de um bicicletário no local, para que os ciclistas possam parar ou mesmo guardar as bicicletas.

\subsection{SETORIZAÇÃO DA ÁREA DO PROJETO}

Para o desenvolvimento da Proposta Projetual do Parque Nações Norte, foi estabelecido um mapa delimitando 4 setores, que poderão delinear e oferecer embasamento às técnicas de Infraestrutura Verde aplicadas. 


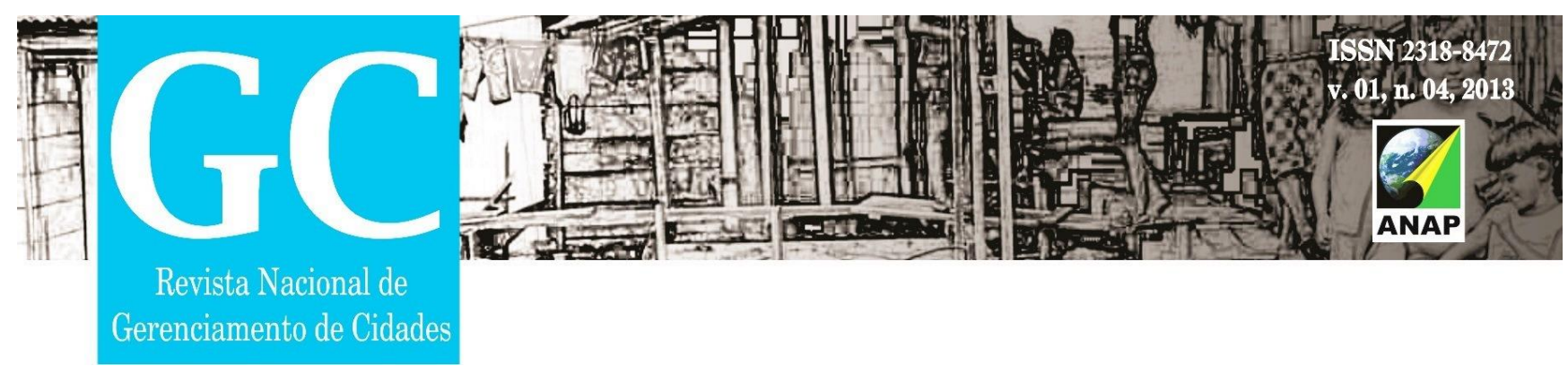

Setor 01 - Nesta área será definida uma quadra de futebol gramada com previsão de possibilidade de alagamento em períodos de intensa pluviosidade. Também será instalado mobiliário urbano adequado para que a população possa contemplar o parque.

Setor 02 - É uma área com uma inclinação bastante expressiva. Desse modo, nessa área serão implantados os gabiões vegetados, pois podem retardar a descida das águas pluviais, e também, diminuir os processos erosivos existentes no terreno.

Setor 03 - Área destinada a receber e a preservar maior parte da vegetação. Serão implantados alguns passeios ao longo deste trecho, para que as pessoas possam utilizá-lo. Também será proposta a instalação de mobiliário urbano no local destinado à população. Além disso, neste setor serão projetadas pequenas áreas alagáveis, podendo funcionar como lagoas pluviais.

Setor 04 - Área do parque que receberá a implantação do bicicletário, podendo dessa maneira estabelecer integração com a ciclovia existente nas Avenidas Nações Norte e Moussa Nakhl Tobias.

\section{CONSIDERAÇÕES FNAIS}

A Infraestrutura Verde torna-se uma nova medida perante aos problemas de drenagem. E, portanto, passa a ser uma forte estratégia frente ao desenfreado crescimento dos atuais centros urbanos e a típica urbanização monofuncional.

A área escolhida no município de Bauru está determinada em uma região de expansão. Desse modo, o desenvolvimento do Projeto do Parque Nações Norte torna premente a necessidade do planejamento de mais áreas espalhadas pelo município de Bauru e em outras cidades do Brasil, que possam desempenhar funções ambientais, para que assim, os problemas urbanos de drenagem pluvial possam ser sanados o mais rápido possível. 


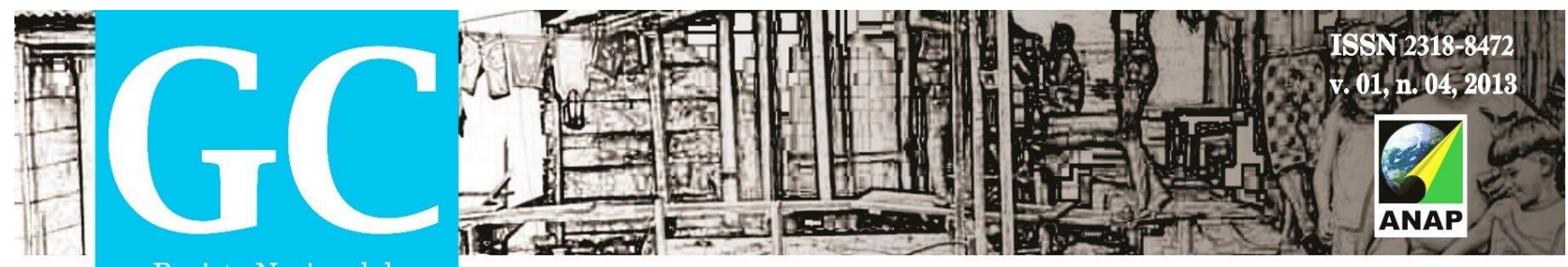

Revista Nacional de

Gerenciamento de Cidades

\section{REFERÊNCIAS}

GORSKI, M. C. B. Rios e cidades: Ruptura e Reconciliação. Livro Rios e Cidades Gorski. São Paulo: Editora Senac São Paulo, 2010.

HERZOG. Infraestrutura Verde, Sustentabilidade e Resiliência Urbana. In: INVERDE, 2010, São Paulo. Palestra... São Paulo: INVERDE, 2010. Disponível em: http://inverde.wordpress.com/pdfs-palestras/>. Acesso em: 12 abr. 2012.

MASCARÓ, J. L.; YOSHINAGA, M. Infra-estrutura urbana. Porto Alegre: Editora Masquatro, 2005.

MIANA, A. C. Adensamento e forma urbana: inserção de parâmetros ambientais de processo de projeto. 2010. 394f. Tese (Doutorado em Tecnologia da Arquitetura) Universidade de São Paulo, 2010. 